\title{
Altered properties of the fibrin gel structure in patients with IDDM
}

\author{
G. J örneskog ${ }^{1,3}$, N . E gberg' ${ }^{2}$, B . Fagrell ${ }^{1}$, K . Fatah ${ }^{2}$, B . H essel ${ }^{2}$, H . J ohnsson ${ }^{1}$, K . B rismar ${ }^{3}$, M . B lombäck ${ }^{2}$ \\ ${ }^{1} \mathrm{D}$ epartment of Internal M edicine, \\ ${ }^{2} \mathrm{D}$ epartment of $\mathrm{L}$ aboratory M edicine, D ivision of C linical Chemistry and B lood Coagulation, and \\ ${ }^{3} \mathrm{D}$ epartment of E ndocrinology and D iabetology, K arolinska H ospital, Stockholm, Sweden
}

Summary High plasma fibrinogen levels are associated with vascular complications in the general population. Fibrin, the structural element in a clot, is derived from fibrinogen by activation of thrombin. A $n$ abnormal fibrin gel structure has been demonstrated in patients with myocardial infarction and in diabetic patients during poor metabolic control. In the present study the properties of fibrin gel structure were investigated in 20 patients with insulin-dependent diabetes mellitus (ID D M ): 10 patients without (age: $30 \pm 8$; diabetes duration: $7 \pm 6$ years), and 10 patients (age: $44 \pm 7$; diabetes duration: $27 \pm 9$ years) with microangiopathy. Fifteen healthy subjects served as controls (age: $40 \pm 8$ years). The glycosylated haemoglobin level $\left(\mathrm{H} \mathrm{bA}_{1 \mathrm{c}}\right)$ was elevated $(\mathrm{p}<0.001)$ in the patients: $6.5 \pm 1.5 \%$ in diabetic patients without, and $7.1 \pm 1.0 \%$ in diabetic patients with microangiopathy. C-reactive protein and plasma fibrinogen were similar as compared to healthy control subjects. The properties of the fibrin gel structure; i.e. the permeability coefficient ( $\mathrm{K} s$ ) and the fibre mass length ratio $(\mu)$ formed in recalcified plasma on addition of thrombin were investigated. Ks was decreased in the diabetic patients, with $\left(6.5 \pm 2.0 \mathrm{~cm}^{2} ; \mathrm{p}<0.01\right)$ and without microangiopathy $\left(6.5 \pm 2.7 \mathrm{~cm}^{2} ; p<0.05\right)$, as compared to healthy subjects $\left(10.0 \pm 3.4 \mathrm{~cm}^{2}\right)$, while $\mu$ was not significantly $(p=0.14)$ altered. The results indicate a lower fibrin gel porosity in patients with IDDM , despite normal plasma fibrinogen and irrespective of microangiopathy. The abnormal fibrin gel structure may be due to an increased glycosylation of the fibrin (-ogen) molecule caused by long-term hyperglycaemia and may be of importance for the development of angiopathy in diabetic patients. [D iabetologia (1996) 39: 1519-1523]

Keywords Diabetes mellitus, fibrinogen, fibrin gel structure.
A high fibrinogen level is an independent risk factor for coronary heart disease, stroke and peripheral arterial disease in the general population [1, 2]. In diabetic patients, there is a $2-3$ fold greater risk of coronary vascular disease and stroke than in the non-diabetic population, and a 3- to 6-fold greater risk of

R eceived: 7 M ay 1996 and in revised form: 9 September 1996

Corresponding author: D r. G.Jörneskog, D epartment of I nternal M edicine, Karolinska H ospital, S-17176 Stockholm, Sweden.

A bbreviations: IDDM, Insulin-dependent diabetes mellitus; $\mathrm{K} s$, permeability coefficient; $\mu$, fibre mass length ratio; CRP, $C$-reactive protein; vWF, von Willebrand factor; t-PA, tissue plasminogen activator. peripheral arterial occlusive disease [3]. The pathophysiological mechanism linking el evated fibrinogen levels to increased risk of vascular complications is not clear. In diabetic patients, elevated plasma fibrinogen levels may also be seen in patients with no evidence of vascular disease $[4,5]$. H owever, it may be difficult to detect the early stages of vascular complications, as it is a process ongoing for several years. The mechanism by which fibrinogen acts is unclear, but it may play a part in the pathogenesis of vascular complications, as the structural element in a clot is derived from fibrinogen. Upon activation with thrombin, fibrinogen molecules form fibrin monomers that polymerize and create a fibrin network [6, 7]. D epending on the conditions prevailing during activation, the gels formed may vary in structure [7]. 
Increased clotting potential or fibrinogen levels may form a more rigid fibrin gel structure, which might be more thrombogenic [8]. The fibrin gel structure has been studied in vitro during standardized conditions and a tighter and less permeable fibrin network with thinner fibrin strands has been found in patients suffering from ischaemic heart disease with a first myocardial infarction before the age of 45 years [9]. Similar changes have been demonstrated in patients with insulin-dependent diabetes (IDDM) during poor metabolic control [10].

The aim of the present study was to investigate if the properties of fibrin gel structure are altered in patients with IDD M, and if any differences could be related to late diabetic complications.

\section{Subjects and methods}

Patients. Two groups of patients with IDDM were investigated; ten patients with and ten without microangiopathy. The basic characteristics are presented in Table 1 . The patients with microangiopathy all had background or preproliferative retinopathy and three patients also had microalbuminuria. None had a history of cardiovascular events or stroke and electrocardiograms and segmental blood pressure (arm, ankle, and toe blood pressure) were normal. A II patients were treated with insulin four times daily, i.e. regular insulin at meal times and $\mathrm{NPH}$ insulin at night. No other medication was given, including drugs containing acetyl salicylic acid or antiflogistics during the 2 weeks before the blood samples were taken. None of the female patients used oral contraceptive agents.

$\mathrm{H}$ ealthy subjects. We investigated 15 healthy control subjects. N one had a family history of diabetes. Their basic characteristics are shown in Table 1. A Il drugs containing antiflogistics or acetyl salicylic acid were avoided during 2 weeks before the blood samples were taken and none of the female participants used any oral contraceptive agents.

Blood tests. Venous blood was taken in the morning after $12 \mathrm{~h}$ fast for determination of glycosylated haemoglobin ( $\mathrm{H} \mathrm{bA}_{1 \mathrm{c}}$ ), plasma fibrinogen, $C$-reactive protein (CRP), von Willebrand factor ag ( $V W F)$, functional tissue plasminogen activator ( $t$ PA ) without stasis, and fibrin gel structure.

$\mathrm{HbA}_{1 \mathrm{c}}$ was analysed by an ELISA -method using monoclonal antibodies from Dakopatts, Dako Diagnostics $L t d$, Cambridge, UK, as was vWF using an A sserachrom vW F kit from Stago, A snieres, France [11]. Plasma C-reactive protein was analysed by Beckman CRP reagents from Beckman, Brea, California, USA, and t-PA with Spectrolyse/fibrin kit from Biopool, U meå, Sweden [12]. Fibrinogen was analysed with a syneresis method measuring total fibrinogen [13]. Fibrin gel structure was assayed as described previously $[7,8]$. The plasma samples were dialysed against TNE-buffer $(0.05 \mathrm{~mol}$ Tris, $0.1 \mathrm{~mol} \mathrm{NaCl}, 1 \mathrm{mmol}$ EDTA buffer, $\mathrm{pH}$ 7.4). The dialysed plasma $(1 \mathrm{ml})$ was recalcified with $\mathrm{CaCl}_{2}$ to give a final concentration of $20 \mathrm{mmol} / \mathrm{ml}$ in the cuvettes, and thrombin was immediately added to reach a clotting time of 45-50 s. The fibrin gels formed in the cuvettes were left to mature in room temperature for $18-24 \mathrm{~h}$ before permeation. Five different hydrostatic pressures were used to percolate a Tris-imidazole buffer $(0.02 \mathrm{~mol} / \mathrm{l}$ Tris, $0.02 \mathrm{~mol} / \mathrm{l}$ imidazole, $0.1 \mathrm{~mol} / \mathrm{l}$
Table 1. Characteristics of diabetic patients and healthy subjects

\begin{tabular}{llll}
\hline & $\begin{array}{l}\text { IDDM } \\
\text { without } \\
\text { complication }\end{array}$ & $\begin{array}{l}\text { IDDM with } \\
\text { complication }\end{array}$ & $\begin{array}{l}\text { Healthy } \\
\text { control } \\
\text { subjects }\end{array}$ \\
\hline $\begin{array}{l}\text { Sex (male/female) } \\
\text { A ge (years) }\end{array}$ & $6 / 4$ & $6 / 4$ & $8 / 7$ \\
$\begin{array}{l}\text { Diabetes duration } \\
\text { (years) }\end{array}$ & $30 \pm 8$ & $44 \pm 7^{\mathrm{a}}$ & $40 \pm 8$ \\
Smokers (n) & $7 \pm 5$ & $27 \pm 9^{\mathrm{b}}$ & - \\
\hline
\end{tabular}

The values are given as mean \pm SD or number.

a $p<0.01 ;{ }^{b} p<0.001$ as compared to IDD M patients without complications

$\mathrm{NaCl}, \mathrm{pH}$ 7.4) through the gel. The permeability coefficient $(\mathrm{K} s)$ and the fibre mass/length ratio $(\mu)$ were determined as described by Blombäck et al. [8]. The reproducibility parameters for the permeability coefficient (K s) and the fibre mass/length ratio $(\mu)$ are in both cases $7 \%$.

Statistical analysis. D ata are given as mean \pm SD. The MannWhitney $U$ test was used to test differences between the groups. A value of $p$ less than 0.05 was considered statistically significant.

The study was approved by the ethics committee of the $\mathrm{K}$ arolinska H ospital and the subjects had given their informed consent.

\section{Results}

The results are shown in Table 2. M etabolic control, as measured by $\mathrm{HbA}_{1 \mathrm{c}}$, was similar in the two patient groups, but significantly elevated $(p<0.001)$ as compared to healthy control subjects. Levels of CRP, plasma fibrinogen and VW $F$ were similar in patients and healthy control subjects. No correlation was seen between $\mathrm{HbA}_{1 \mathrm{~b}}$ and plasma fibrinogen $(r=0.20$; $p=0.44)$. The permeability coefficient $(\mathrm{K} \mathrm{s})$ was significantly lower in the diabetic patients, both in patients with $(p<0.01)$ and without $(p<0.05)$ microangiopathy, as compared to the healthy control subjects (Fig.1). A mong the patients, the highest $\mathrm{Ks}$ value (12.3) was found in one patient with a short diabetes duration of 25 months, who was in remission $\left(\mathrm{HbA}_{1 \mathrm{c}}\right.$ $4.1 \%$ ) and without insulin therapy for 3 months. This patient is marked with * in the figures. A $n$ inverse correlation was found between $\mathrm{HbA}_{1 \mathrm{c}}$ and the permeability coefficient (K s) when patients and healthy control subjects were counted together $(r=-0.53$; $p=0.001)$. This correlation was not significant $(r=-$ $0.36 ; p=0.11$ ) when the healthy control subjects were excluded from the calculations (Fig.2). The fibre mass length ratio $(\mu)$ was not significantly $(p=14)$ altered in the patients, as compared to healthy control subjects (Fig. 3), and there was no correlation between $\mathrm{HbA}_{1 \mathrm{c}}$ and fibre mass length ratio $(\mu)$ (Fig. 4). 
Table 2. L aboratory tests in diabetic patients and healthy subjects

\begin{tabular}{|c|c|c|c|}
\hline & $\begin{array}{l}\text { IDDM } \\
\text { without } \\
\text { complication }\end{array}$ & $\begin{array}{l}\text { IDDM with } \\
\text { complication }\end{array}$ & $\begin{array}{l}\text { H ealthy } \\
\text { control } \\
\text { subjects }\end{array}$ \\
\hline $\mathrm{n}$ & 10 & 10 & 15 \\
\hline $\mathrm{HbA}_{1 \mathrm{c}}(\%)$ & $6.5 \pm 1.5^{c}$ & $7.1 \pm 1.0^{c}$ & $3.7 \pm 0.5$ \\
\hline C-reactive protein $(\mathrm{mg} / \mathrm{l})$ & $5.5 \pm 2.3$ & $4.9 \pm 0.3$ & $4.9 \pm 1.0$ \\
\hline Plasma fibrinogen ( $\mathrm{g} / \mathrm{l}$ ) & $3.1 \pm 0.6$ & $3.2 \pm 0.7$ & $3.0 \pm 0.6$ \\
\hline $\begin{array}{l}\text { Permeability coefficient, } \\
\mathrm{K} \mathrm{s}\left(\mathrm{cm}^{2} \times 10^{9}\right)\end{array}$ & $6.6 \pm 2.7^{a}$ & $6.5 \pm 2.1^{b}$ & $10.0 \pm 3.4$ \\
\hline $\begin{array}{l}\text { Fibre mass length ratio, } \\
\mu\left(\mathrm{D} \mathrm{a} / \mathrm{cm} \times 10^{-12}\right)\end{array}$ & $108 \pm 61$ & $112 \pm 52$ & $134 \pm 59$ \\
\hline $\begin{array}{l}\text { von Willebrand Factor } \\
\text { (IU/ml) }\end{array}$ & $0.98 \pm 0.22$ & $0.87 \pm 0.16$ & $0.88 \pm 0.22$ \\
\hline $\begin{array}{l}\text { Tissue plasminogen } \\
\text { activator (IU /ml) }\end{array}$ & $0.67 \pm 0.35$ & $0.64 \pm 0.29$ & $0.44 \pm 0.13$ \\
\hline
\end{tabular}

Values are given as mean \pm SD.

${ }^{a} p<0.05 ;{ }^{b} p<0.01 ;{ }^{c} p<0.001$ as compared to healthy controls

\section{Discussion}

The results of the present study show altered properties of the fibrin gel structure in patients with IDDM, despite normal plasma fibrinogen levels, no evidence of macroangiopathy, and irrespective of microangiopathy. N one of the patients had any signs of ongoing inflammation or infection and the acute phase reactant CR P was normal. The VWF and t-PA levels were within the normal range, indicating a normal endothelial cellular function. The altered fibrin gel structure was characterized by a reduced permeability coefficient $(\mathrm{K} \mathrm{s})$, while the fibre mass length ratio $(\mu)$ was not significantly decreased $(p=0.14)$.

D iabetes is associated with a thrombophilic state [14] and several epidemiological studies have shown that diabetic patients more rapidly develop thromboembolic events [15]. The plasma fibrinogen level is frequently elevated in diabetes and particularly in patients with vascular complications and impaired metabolic control [4]. The exact mechanism by which fibrinogen acts is not clear, but fibrinogen is the final common denominator of the clotting process that occurs at sites of lesions in the blood vessel wall, and may therefore be of pathophysiological importance for the atherosclerotic process and not only a secondary marker of this process. The structure of a clot is made by fibrin, which is derived from fibrinogen when activated by thrombin. The properties of fibrin gel structure depend on the conditions prevailing during activation [8, 16-19] and the fibrin gel structure may vary between two extremes; i.e. thin fibre strands with small liquid spaces in between and thicker fibre strands with large pores [6, 7]. A Iterations in the fibrin gel structure have been described in diabetic patients during poor metabolic control [10] and

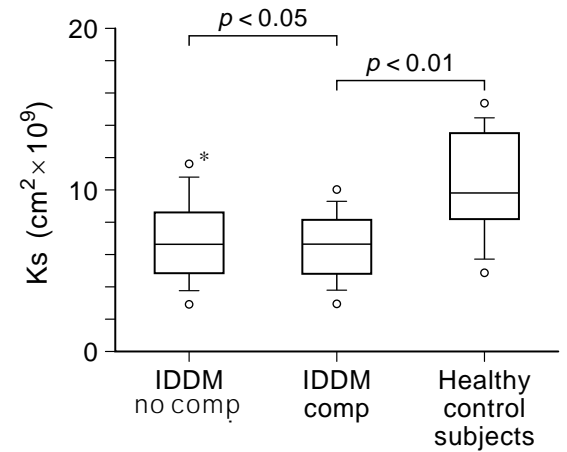

Fig. 1. Permeability coefficient (Ks) of fibrin gel structure in 10 diabetic patients without complications, 10 diabetic patients with complications and 15 healthy control subjects. Box-plot showing median values and the 10th, 25th, 75th and 90th percentiles. The patient marked $*$ is in remission and without insulin treatment for 3 months

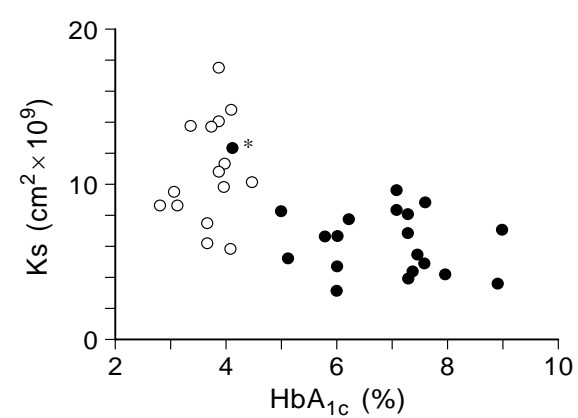

Fig. 2. Relation between metabolic control $\left(\mathrm{HbA}_{1 \mathrm{c}}\right)$ and permeability coefficient (K s) in 20 patients with IDDM (•) and 15 healthy control subjects (0). The patient marked $*$ is in remission and without insulin treatment for 3 months

in patients suffering a myocardial infarction before the age of 45 [8]. In these two studies, the permeability coefficient (Ks) and fibre mass/length ratio $(\mu)$ were both decreased $[9,10]$. A low permeability coefficient (K s) indicates a tighter fibrin gel architecture, while a decreased fibre mass length ratio $(\mu)$ indicates a reduced fibre strand diameter and differences in hydration [7]. These changes have also been demonstrated by three-dimensional microscopy [8]. The properties of the fibrin network contribute to the regulation of the fibrinolytic rate, e. g. a decrease in fibre size is associated with a reduced fibrinolytic rate [20]. The reason may be that a tighter and more rigid fibrin gel structure decreases the availability of fibrinolytic enzymes to reach their binding sites leading to impaired fibrinolysis $[10,21]$ and vascular complications.

In the present study, the plasma fibrinogen levels were normal in both patient groups, despite a mean diabetes duration of 27 years in the patients with microangiopathy. Elevated levels have earlier been shown in diabetic patients with retinopathy [5], so the findings are somewhat surprising, but may indicate that we have investigated a "healthy" group of 


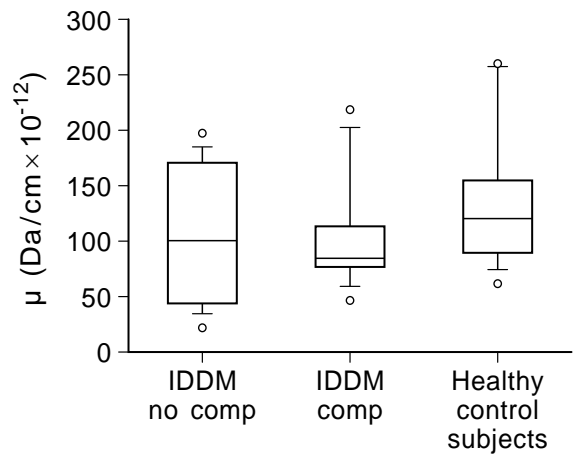

Fig. 3. Fibre mass length ratio $(\mu)$ of fibrin gel structure in 10 diabetic patients without complications, 10 diabetic patients with complications and 15 healthy control subjects. Box-plot showing median values and the 10th, 25th, 75th and 90th percentiles

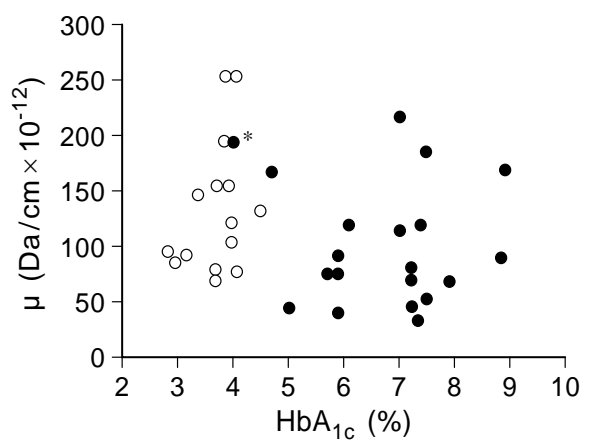

Fig. 4. Relation between metabolic control $\left(\mathrm{HbA}_{1 \mathrm{c}}\right)$ and fibre mass length ratio $(\mu)$ in 20 patients with IDDM (•) and 15 healthy control subjects (0). The patient marked with * is in remission and without insulin treatment for 3 months

diabetic patients. The normal levels of vW $F$ and t-PA also support this. The plasma fibrinogen values seen in our patients may be positively influenced by the fairly good metabolic control in these patients, as the level of plasma fibrinogen is related to the metabolic control in patients with diabetes [4]. However, despite normal fibrinogen levels and no evidence of macrovascular disease, the properties of the fibrin gel structure were altered in our diabetic patients. The permeability coefficient ( $\mathrm{K} \mathrm{s}$ ) was significantly lower irrespective of late diabetic complications, while the fibre mass/length ratio $(\mu)$ was not significantly reduced, indicating a tighter fibrin gel structure than normal, but with fibre strands of normal thickness. However, a tendency towards lower fibrin mass/length ratio $(\mu)$ can be suspected in the patients with complications (Fig.3) and the normal fibrin mass length ratio $(\mu)$ in this patient group may be due to a type II error. In the study by $\mathrm{N}$ air et al. [10], who investigated diabetic patients during poor metabolic control, both permeability coefficient (K S) and fibre mass length ratio $(\mu)$ were decreased. The reason for this discrepancy, as compared to the present study, may be related to a type II error as described above, or to differences in metabolic control, plasma fibrinogen level, and/or late complications. No information regarding plasma fibrinogen levels and late diabetic complications are available in the study by Nair et al. [10].

The exact mechanism behind the altered fibrin gel structure in patients with diabetes is not known, but hyperglycaemia is most likely an important factor. A decreased permeability of the fibrin network has been demonstrated in vitro when glucose is added to normal plasma [10]. Proteins undergo increased glycosylation when exposed to supranormal glucose levels and the functionality of the molecule may be altered [22]. This mechanism has been shown in vitro for antithrombin [23]. Fibrinogen appears to be only slightly glycosylated in non-diabetic subjects, but to a greater extent in diabetic patients [24].

The alteration of the fibrin gel structure seems to start early after onset of diabetes, as the patients without microangiopathy demonstrated similar changes as the patients with microangiopathy, despite younger age and shorter diabetes duration. One patient showed a markedly higher permeability coefficient $(\mathrm{K} \mathrm{s})$ than the other patients. This patient had the shortest diabetes duration ( 25 months) and had been without insulin therapy for 3 months because of sufficient endogenous insulin production. $\mathrm{H}$ er $\mathrm{HbA}_{1 \mathrm{c}}$ was also normal. It could be argued that this patient should be excluded from the study since she is C-peptide positive. $\mathrm{H}$ owever, as this patient had a diabetes debut typical for ID D M we think the results are of interest, as it supports the hypothesis that hyperglycaemia influences fibrin gel structure.

In conclusion, the present study shows an altered fibrin gel structure in patients with IDDM and irrespective of microangiopathy. The fibrin gel structure was characterized by a reduced permeability coefficient (K s), indicating a less porous fibrin network. In contrast to earlier findings in non-diabetic patients, this alteration in fibrin gel structure was seen despite normal plasma fibrinogen levels and no evidence of macroangiopathy. The altered fibrin gel structure may be due to increased glycosylation of fibrinogen and fibrin and may be of importance for the development of angiopathy in diabetic patients. A cetyl salicylic acid seems to improve the properties of fibrin gel structure in non-diabetic patients with stable angina pectoris [21, 25] and may therefore be of importance for the treatment of vascular diseases. If it is possible to improve the properties of the fibrin gel structure with acetyl salicylic acid also for patients with diabetes this has not been investigated to our knowledge.

A cknowledgements. This work was supported by grants from Swedish M edical Research Council (no 6835), N ovo Nordisk Foundation, Swedish Society for Medical R esearch, Swedish $\mathrm{D}$ iabetes A ssociation, and K arolinska Institute. 


\section{References}

1. Kannel W B , D 'A gostino R B, B elanger A J (1987) Fibrinogen, cigarette smoking and risk of cardiovascular disease: insights from the Framingham Study. A m Heart J 113: 1006-1010

2. Wilhelmsen L, Svardsudd K, Korsan-B engsten K, L arsson B, Welin L, Tibblin G (1984) Fibrinogen as a risk factor for stroke and myocardial infarction. New Engl J Med 311: 501-505

3. Kannel WB, M cG ee DL (1979) D iabetes and cardiovascular disease. The Framingham study. JA M A 19: 2035-2038

4. G anda O P, A rkin CF (1992) H yperfibrinogenemia. A n important risk factor for vascular complications in diabetes. D iabetes Care 15: 1245- 1250

5. L owe GD O, L owe J M , D rummond M M et al. (1980) B lood viscosity in young male diabetics with and without retinopathy. D iabetologia 18: 359-363

6. Ferry J D, M orrison PR (1947) Preparations and properties of serum and plasma proteins. The conversion of human fibrinogen to fibrin under various conditions. J A mer Chem Soc 69: 388-400

7. Blombäck B, Carlsson K, Fatah K, H essel B, Procyck R (1994) Fibrin in human plasma: gel architectures governed by rate and nature of fibrinogen activation. Thrombosis Research 5: 521-538

8. B lombäck B, Carlsson K, H essel B, L iljeborg A, Procyk R, A slund N (1989) N ative fibrin gel networks observed by 3D microscopy, permeation and turbidity. Biochim Biophys A cta 997: 96-110

9. Fatah K, H amsten A , Blombäck B, B lombäck M (1992) Fibrin gel net work characteristics and coronary heart disease: relations to plasma fibrinogen concentration, acute phase protein, serum lipoproteins and coronary atherosclerosis. Thromb H aemost 68: 130-135

10. Nair CH, A zhar A, Wilson J D, D hall DP (1991) Studies on fibrin network structure in human plasma. Part II - Clinical application: Diabetes and antidiabetic drugs. Thromb R es 64: 477-485

11. A miral J, A dalbert B , A dam M (1982) A pplication of enzyme immunoassays to coagulation testing. Clin Chem 30: 1512-1516
12. R ånby $M, N$ orrman $B$, Walle'n P (1982) A sensitive assay for tissue plasminogen activator. Thromb Research 27: 743-749

13. Blombäck B, B lombäck M (1956) Purification of human and bovine fibrinogen. A rkiv K emi 10: 415-443

14. Ceriello A (1993) Coagulation activation in diabetes mellitus: the role of hyperglycaemia and therapeutic prospects. D iabetologia 36: 1119-1125

15. Colwell J (1993) Vascular thrombosis in type II diabetes mellitus. D iabetes 42: 8-11

16. B lombäck B , O kada M (1982) Fibrin gel structure and clotting time. Thromb R es 25: 51-70

17. O kada M, Blombäck B, B lock M (1983) E ffect of albumin and dextran on fibrin gel structure. Thromb Haemost 50 : 201 ( $A$ bstract)

18. O kada M, Blombäck B, Chang M .-D., Horowitz B (1985) Fibronectin and fibrin gel structure. J Biol Chem 260: 1811-1820

19. O kada M , B lombäck B (1983) Calcium and fibrin gel structure. Thromb R es 29: 269-280

20. Gabriel DA, M uga K, B oothroyd EM (1992) The effect of fibrin structure on fibrinolysis. J Biol Chem 267 (34): 24259-24263

21. Williams S, Fatah K , I vert T, B lombäck M (1995) The effect of acetyl salicylic acid on fibrin gel lysis by tissue plasminogen activator. Blood Coagulation and Fibrinolysis 6: 718725

22. M cM illan DE (1992) Clotting disorders in diabetes. In: A Iberti K G M M , D eFronzo RA, K een H, Z immet P (eds) International textbook of diabetes mellitus. John Wiley \& Sons L td Chichester 2: 1447-1457

23. Villanueva G B, A llen N (1988) D emonstration of altered anti-thrombin III activity due to non enzymatic glycosylation at glucose concentration expected to be encountered in severely diabetic patients. D iabetes 37: 1103-1107

24. L utjens A, Velde A A, Veen E A, M eer J (1985) G lycosylation of human fibrinogen in vivo. D iabetologia 28: 87-89

25. Fatah K, B eving H, A lbåge A, I vert T, B lombäck M (1996) A cetylsalicylic acid may protect the patient by increasing fibrin gel porosity. I s withdrawing of treatment harmful to the patient? E ur H eart J 17: 1362-1366 